Article

\title{
Studies of Water-Vapour Adsorption Dynamics of High-Efficiency Desiccant Based on Aluminium Oxide and NaX Zeolite
}

\author{
Eugene Meshcheryakov ${ }^{1}$, Maxim Kozlov ${ }^{2}$, Sergey Reshetnikov ${ }^{2}{ }^{(}$, Lyubov Isupova ${ }^{2}$, \\ Alesia Livanova ${ }^{1}$ and Irina Kurzina ${ }^{1, *(D)}$ \\ 1 Faculty of Chemistry, National Research Tomsk State University, Tomsk 634050, Russia; \\ meevgeni@mail.ru (E.M.); truelivanova@mail.ru (A.L.) \\ 2 Boreskov Institute of Catalysis, Siberian Branch, Russian Academy of Sciences, Novosibirsk 630090, Russia; \\ kvn@catalysis.ru (M.K.); reshet@catalysis.ru (S.R.); isupova@catalysis.ru (L.I.) \\ * Correspondence: kurzina99@mail.ru; Tel.: +7-913-882-1028
}

Received: 1 July 2020; Accepted: 28 July 2020; Published: 31 July 2020

\begin{abstract}
The dynamic capacity of the commercial desiccant ( $\mathrm{NaX}$ zeolite) and the adsorbent, synthesised based on low-temperature modifications of aluminium oxide, obtained from bayerite-containing hydroxide, was determined with respect to water vapour. Experimental studies were carried out using a pilot installation at the atmospheric pressure and increased pressure (up to $0.6 \mathrm{MPa}$ ) and high humidity. The increase in the height of the layer of the adsorbents leads to an increase of their dynamic capacity with respect to water vapour and the protective power (action) time of the layer. It was shown that at the atmospheric pressure and the pressure of up to $0.3 \mathrm{MPa}$, the dynamic capacity of $\mathrm{NaX}$ is greater; at a higher pressure, the adsorption capacity of the developed adsorbent $\mathrm{Al}_{2} \mathrm{O}_{3}$ becomes greater than the zeolite capacity, which allows recommending it as a desiccant at increased pressure.
\end{abstract}

Keywords: aluminium oxide; desiccant; alkaline modification; dynamic capacity

\section{Introduction}

Industrial development is attracting more and more attention to the adsorption of gases and vapour, which has already become a relevant problem in many processing industries. This definitely affects the quality of the product [1,2]. The most common method for removing moisture is the adsorption process, since it is less energy intensive. The adsorption process can be physical or chemical; physisorption is preferable as it allows a low temperature regeneration of the adsorbent [2].

The adsorption process, as a surface phenomenon, usually involves a porous solid medium as the basis of the process in which a multicomponent mixture of liquid (liquid or gas) is attracted to a solid surface by either chemical or physical bonds. Since the adsorption process depends on the nature of the adsorbent, the adsorbent must have a good adsorption capacity and kinetics. Adsorbents with a small pore size (reasonable porosity) and with a large network of pores that allow molecules to penetrate into the adsorbent make the adsorbent suitable for a successful adsorption process $[3,4]$.

Contact-sorption drying integrates two drying techniques: classical contact drying, where the moisture is evaporated using heat conducted from a heated solid surface, and sorption drying (adsorption drying) where moisture transfer is driven by a mass concentration gradient between the material being dried and the adsorbent material it is contacted with. A very general scheme of contact-sorption drying comprises mixing a solid sorbent with the material being dried, followed by separation of these two media once the desired mass transfer has taken place. The solid sorbent is then 
regenerated and returned to the process. Clearly, the technical justification for contact-sorption drying depends on whether the sorbent can easily be regenerated and recycled [5].

As a rule, silica gel, active aluminium oxide, and zeolites are used as an adsorbent-desiccant of different gases, such as compressed air and hydrocarbon-containing gases [6-14]. It is known that zeolites possess some advantages over other adsorbents, in particular, a possibility of dewatering at low partial water pressures, a stable and high degree of dewatering, and a good mechanical strength. However, considering quite a high temperature of their regeneration, it is expedient to carry out dewatering, using a cheaper and more easily regenerated adsorbent, and deep final dewatering, using zeolites [6].

The use of metastable low-temperature forms of aluminum oxide for drying moisture-containing gases is due to their defective structure with many adsorption centers [15]. Desiccants based on aluminium-oxide are characterised by quick regeneration at temperatures in the range of $200-250{ }^{\circ} \mathrm{C}$, by resistance to condensed moisture in humid environments, by high static capacity, relative easiness of obtainment, and accessibility of raw materials. When using aluminium oxide as a protective layer in the adsorber, condensed moisture and chemical impurities will be sorbed from gases upon it, including water vapour, and deep air dewatering will take place in the primary layer of the desiccant-zeolite. It can be expected that the use of a more efficient desiccant as a protective layer will allow not only protecting the primary layer against condensed moisture, but also enhancing the overall performance of the adsorber. It is known that the application of the energy saving method for obtaining a sorbent by means of thermal activation of gibbsite in reactors with a rotating heating surface without the use of traditional "pneumatic transport" leads to its cost saving, and the introduction of various modifying additions in the composition of the adsorbents, obtained by this technology, allows increasing the sorption capacity of aluminium oxides [16-27].

It was previously shown [28] that the modification of the adsorbent desiccant, based on bayerite with potassium and sodium cations, at the stage of hydrating the products of thermal activation of gibbsite allows obtaining adsorbent desiccants with high values of static (more than $20 \mathrm{~g} / 100 \mathrm{~g}$ ) and dynamic (more than $5.0 \mathrm{~g} / \mathrm{cm}^{3}$ ) capacity with respect to water vapour. As a result of the optimisation of the conditions (the nature and the alkali content at the stage of hydration of the gibbsite thermal activation product and the acid module value at the stage of preparation of the moldable paste) of the desiccant preparation, a new desiccant was obtained that surpasses foreign and Russian analogues in dynamic capacity (DC) at similar values of the specific surface area (about $300 \mathrm{~m}^{2} / \mathrm{g}$ ) and static capacity (20-22 g/100 g) [29]. The desiccant is characterised by high strength (more than $8.0 \mathrm{MPa}$ ).

The necessary stage in the research works is scaling when proceeding from laboratory to industrial solutions in order to minimise risks, and to test the technology in conditions modelling the industrial ones. When calculating adsorption apparatuses for various purposes, the static, kinetic and dynamic characteristics of adsorption processes are taken into account. One of the main tasks in the design calculation of the adsorber is to determine the adsorption capacity for specific conditions of the processes. The dynamic capacity of the adsorbent layer acts as such characteristic.

This paper presents the results of the experimental studies on water-vapour adsorption using a pilot installation applying an industrial desiccant-zeolite $\mathrm{NaX}$-and a developed, highly efficient adsorbent based on aluminum oxide. The aluminum oxide adsorbent was obtained on the basis of the product of centrifugal thermal activation of gibbsite modified with sodium cations at the stage of hydration, followed by heat treatment.

As industrial zeolite-based adsorbents-desiccants, $\mathrm{NaX}$ and $\mathrm{NaY}$, which are often used, exhibit similar adsorption capacity for water due to their hydrophilic properties, large surface area and large amount of water. NaY zeolites have increased acid resistance and therefore are most in demand for gas, acidic components. A sample of zeolite of the NaX type has been shown earlier [30] by a high value of the adsorption capacity in water.

The purpose of the work was to study the dynamic capacity of the developed high-performance sample of the aluminium oxide desiccant in conditions approximated to industrial ones (in terms of 
high pressure and humidity) and to compare its adsorption characteristics with those of the commercial adsorbent based on the zeolite $\mathrm{NaX}$ in similar conditions.

\section{Experimental Section}

\subsection{Synthesis of $\mathrm{Al}_{2} \mathrm{O}_{3}$ Adsorbent}

Hydrargillite was used as the initial powder raw material for the synthesis of the alumina adsorbent. The product of centrifugal thermal activation of hydrargillite (CTA HG) was obtained in a drum-type centrifugal flash reactor (CEFLAR ${ }^{\mathrm{TM}}$ ) at a temperature of heaters reaching $615^{\circ} \mathrm{C}$, a drum rotation speed of $60 \mathrm{rpm}$ and a hydrargillite flow rate of $40 \mathrm{~kg} / \mathrm{h}$. The CTA HG product was hydrated in a reactor with a volume of $0.16 \mathrm{~m}^{3}$ and constantly stirred. The temperature range of the process was 90-95 ${ }^{\circ} \mathrm{C}$ and it lasted at atmospheric pressure for $6 \mathrm{~h}$ in an alkaline medium $(\mathrm{NaOH})$; the ratio of solid and liquid phases was $\mathrm{S}: \mathrm{W}=1: 4, \mathrm{pH} 10 \div 12$. After hydration, the low-temperature heat treatment of the filtered mass was carried out in the oven with forced convection for $24 \mathrm{~h}$ at a temperature of $120^{\circ} \mathrm{C}$. The dried mass was being ground in the ball mill for $8 \mathrm{~h}$. As a result of the process, aluminum hydroxide with a powder particle size of 5-25 microns was obtained. Next, the crushed aluminum hydroxide was poured into the mixer with Z-shaped blades; the aqueous solution of the electrolyte-peptizer was poured $\left(\mathrm{HNO}_{3}\right)$ and mixed to obtain a plastic mass suitable for molding by extrusion. The finished plastic mass was pressed through the die to obtain cylindrical granules of different diameters. The granules were heat treated with dried air (the dew point temperature was minus $40{ }^{\circ} \mathrm{C}$ ) in the 5 -liter tube furnace at $420{ }^{\circ} \mathrm{C}$ for $4 \mathrm{~h}$, the air volumetric flow rate was $5000 \mathrm{~h}^{-1}$. According to the $\mathrm{X}$-ray analysis, the resulting adsorbent was a mixture of low-temperature modifications of alumina- $60-70 \%(\gamma+\eta)-\mathrm{Al}_{2} \mathrm{O}_{3}+30-40 \% \chi-\mathrm{Al}_{2} \mathrm{O}_{3}[30]$.

\subsection{NaX Adsorbent}

The water-vapour adsorption studies were carried out for an industrial sample of the zeolite $\mathrm{NaX}$ (cylindrical granules with a diameter of $4.2 \mathrm{~mm}$ and a length of $4.4 \mathrm{~mm}$; the protective action time was $100 \mathrm{~min}$, the minimum dew point temperature was $-56.9^{\circ} \mathrm{C}$, the specific surface area was $624 \mathrm{~m}^{2} / \mathrm{g}$, the pore volume was $0.3 \mathrm{~cm}^{3} / \mathrm{g}$, the pore diameter was $1.94 \mathrm{~nm}$ ) [30] and the developed highly effective adsorbent. The molar ratio of $\mathrm{Si} / \mathrm{Al}$ in the zeolite $\mathrm{NaX}$ was in the range of 1.0-1.4.

\subsection{Adsorbents Test}

The experimental studies on the adsorption of water vapour were carried out on the pilot installation, the schematic diagram of which is shown in Figure 1. It consisted of the following blocks: A dosage block of material flows:

- the air was supplied to the flowmass-controller (1), the rotameter (P1), the manometer (M1); the air consumption could vary in the range from 0 to $15,000 \mathrm{~L} / \mathrm{h}$.

An air humidification block:

- the saturator (2) represented a vertical cylinder apparatus with a diameter of $100 \mathrm{~mm}$ and a height of $1000 \mathrm{~mm}$. The air was supplied through the tube with holes of $1 \mathrm{~mm}$ in diameter. Attachments (Rashig rings) were loaded into the saturator and water was poured; volumes varied depending on the experimental conditions;

- the mist separator (3) represented a vertical cylindrical apparatus with a diameter of $85 \mathrm{~mm}$ and a height of $800 \mathrm{~mm}$. The humidified air was supplied through the tube;

- the manometer (M2) was used to control the absence of the excessive pressure in the system.

A block of dewatering of the humidified air:

- the adsorber (4) represented a vertical cylindrical apparatus with a diameter of $50 \mathrm{~mm}$, a height of $800 \mathrm{~mm}$ and a volume of $2 \mathrm{~L}$. A required volume of the sorbent was loaded in it. An air 
distribution grill was installed on the bottom flange. A thermocouple pocket (a 5-mm diameter tube welded at one end) was coaxially placed inside the adsorber. The dry air was discharged into the atmosphere through the valve (B3) and the rotameter (P3). The manometer (M3) controlled the excessive pressure.

A block of analytical control of the technological parameters of the dry air:

- the valve (B1) was attached to the exit nozzle (4) of the adsorber. It was used for sampling when measuring the parameters of the humidified air at the exit from the adsorber;

- the rotameter (P2) was used to control the air consumption, which changed in the range from $0 \%$ to $100 \%$ of the scale;

- the hygrometer (5) measured the parameters of the ingoing air;

- the thermocouple (T1) and the personal computer were used to control the temperature of heating of the adsorbent layer;

- the valve (B2) was intended for sampling when measuring the parameters of the humidified air at the entrance to the adsorber;

- the valve (B3) was applied to create excessive pressure in the system.

The dry air from the system, passing through the rotameter (P1), was dosed by means of the flow-mass controller (1) into the saturator (2), where the air was saturated with water vapour. Then the humidified gas flow entered the mist separator (3), where the excessive condensed moisture was removed. Having left the mist separator, the humidified air entered the adsorber (4). The adsorbent, loaded to the adsorber, absorbed the moisture from the ingoing air. A small amount of the air was collected by the hygrometer (5) through the rotameter (P2) for the analysis; the rest of the air was discharged into the atmosphere through the rotameter (P3). The pilot plant allows conducting experiments at an increased pressure and loading the adsorbent in the volume of 2 litres, and at the same time allows obtaining dry air at the exit at a dew point not exceeding minus $40^{\circ} \mathrm{C}$.

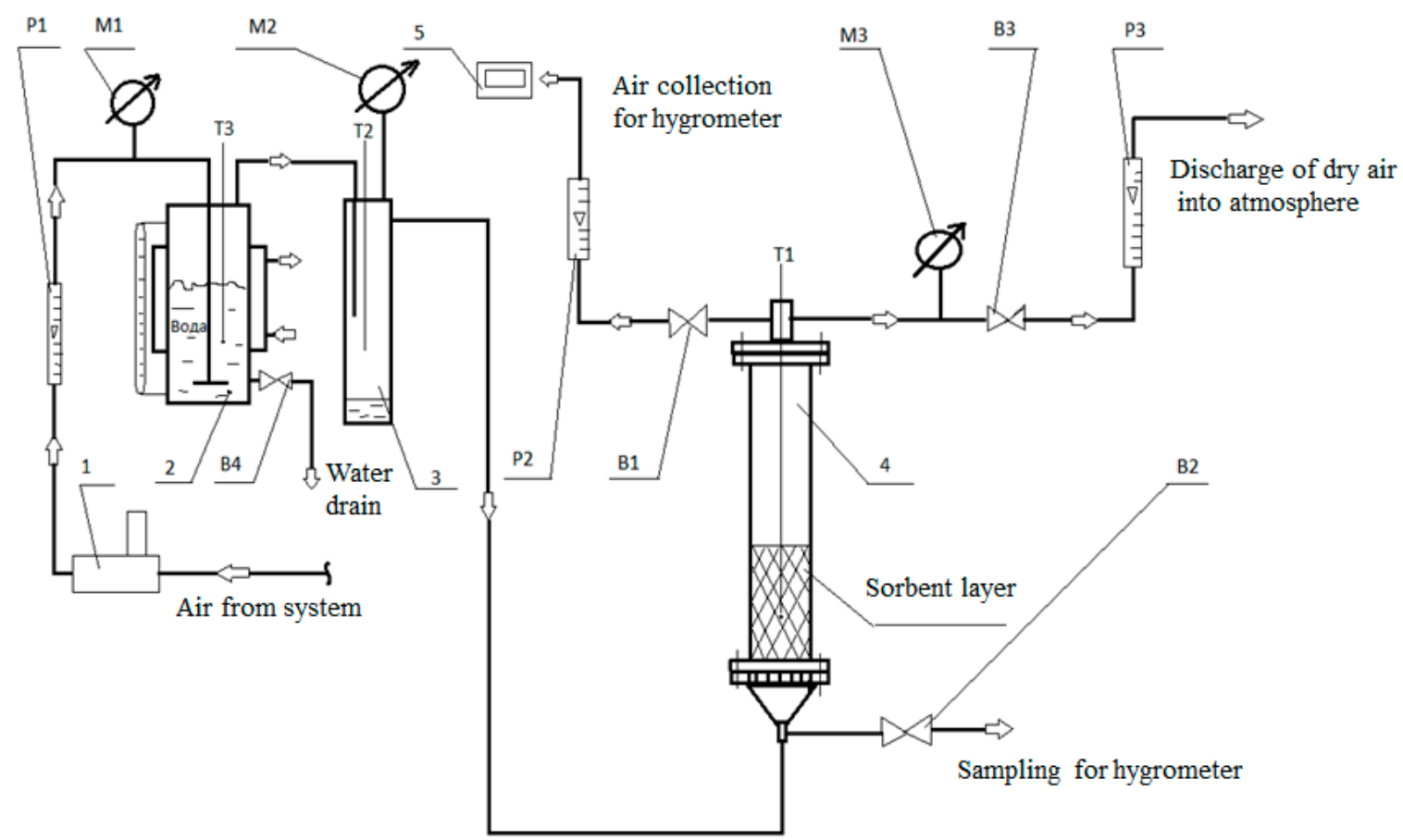

Figure 1. Schematic diagram of the pilot plant. 1-flow-mass controller; 2-saturator; 3-mist separator; 4-adsorber; 5-hygrometer; P1,P2,P3-rotameters; B1,B2,B3-valves; M1,M2,M3-manometers; T1,T2,T3-signalising thermocouples. 
The dynamic capacity of the adsorbents was determined by the amount of water absorbed by the adsorbent by the moment when the moisture content in the gas at the exit from the adsorber had reached the dew point of $-40{ }^{\circ} \mathrm{C}$ (the protective power time of the layer). The dew point temperature was determined using the hygrometer Cermet II ("Michell Instruments Ltd.", Lancaster, UK) in the measurement range from -100 to $+20^{\circ} \mathrm{C}$.

\section{Results and Discussion}

\subsection{Analysis of Influence of Diffusion Resistance}

The essential condition of successful usage of the adsorbents is the determination of the scope of the process behaviour, where external diffusion resistance is absent. For that, the experimental research was preliminarily conducted on the laboratory unit to determine the linear velocity of gas supply, providing the absence of the external diffusion. According to the data in Figure 2, it is visible that when the linear velocity of the gas flow in the adsorber increases, both at the contact time of $0.6 \mathrm{~s}$ and at the contact time of $1.1 \mathrm{~s}$, the adsorption capacity of the sample increases monotonically. At the velocity equal to $\sim 0.20 \mathrm{~m} / \mathrm{s}$, the adsorption capacity stops changing, which indicates the fact that external diffusion (mass transfer) does not influence the adsorption process any more. Generally, the influence of the supply of the substance from the flow to the external surface of the adsorbent granules is practically excluded at the flow rate of $0.25 \mathrm{~m} / \mathrm{s}[1,8]$.

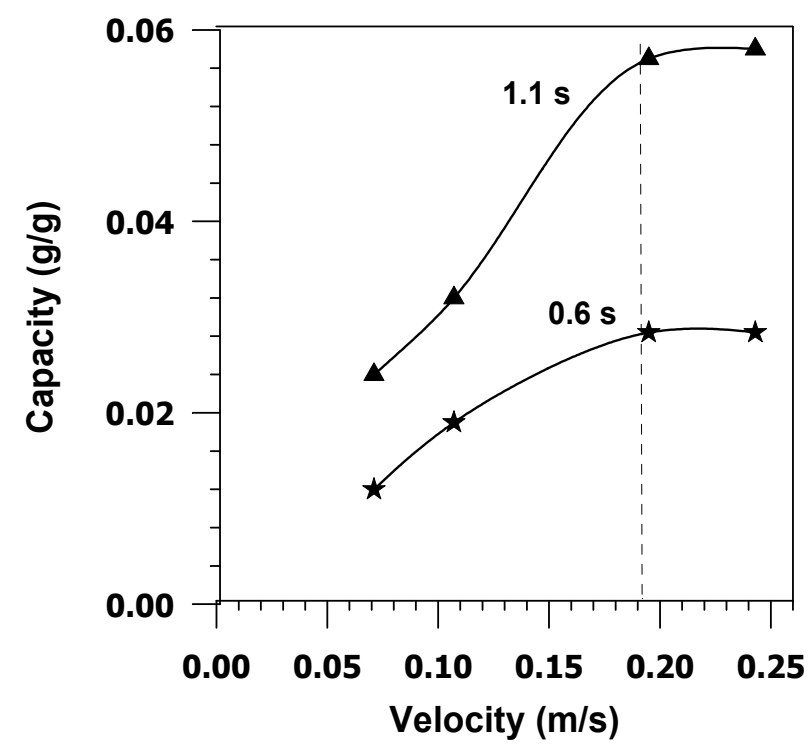

Figure 2. Dependence of the dynamic capacity of the prospective aluminium-oxide adsorbent on the linear velocity of the gas flow in the adsorber of the laboratory unit at different time contacts: $1.1 \mathrm{~s}$ and $0.6 \mathrm{~s}$ (conditions: the saturator temperature is $18{ }^{\circ} \mathrm{C}$, pressure is $0.1 \mathrm{MPa}$ ).

To correctly interpret the experimental data, the experiment must be conducted in similar conditions and with the same ingoing water concentration. The experimental data, obtained at a temperature of $\sim 18^{\circ} \mathrm{C}$ in the saturator, were taken into account, which allowed providing $14.6 \div 15.5 \mathrm{~g} / \mathrm{m}^{3}$ of the water content in the flow at the entrance to the adsorber. Hydrodynamical similarity-homogeneity of the layer filling (constant bulk density of the adsorbent)-was also provided. An important characteristic of the used sorbent was the temperature of its regeneration. Earlier, in [30] the adsorption characteristics of the prospective adsorbent based on aluminium oxide were presented at different temperatures of its regeneration $\left(110{ }^{\circ} \mathrm{C}, 150{ }^{\circ} \mathrm{C}, 270{ }^{\circ} \mathrm{C}\right)$. It was shown that even after desiccant regeneration at $110^{\circ} \mathrm{C}$, its dynamic capacity by water exceeded the values, obtained for the foreign analogue, and the maximal values of the dynamic capacity were obtained when using the training temperature of 
$270{ }^{\circ} \mathrm{C}$. In this connection, before conducting the mentioned tests, the samples $\mathrm{Al}_{2} \mathrm{O}_{3}$ were subjected to thermal treatment at $270{ }^{\circ} \mathrm{C}$ for $2 \mathrm{~h}$ in the inert gas ambient (nitrogen). Before tests, the zeolite was trained at a temperature of $350^{\circ} \mathrm{C}$ for two hours in the inert gas ambient (nitrogen).

All the experiments presented hereafter were conducted on the pilot installation for two adsorbents: the prospective aluminium oxide adsorbent $\left(\mathrm{Al}_{2} \mathrm{O}_{3}\right)$ and the commercial foreign adsorbent, based on the zeolite $(\mathrm{NaX})$. The grain dimensions of the aluminium oxide adsorbent were: diameter- $3.55 \mathrm{~mm}$, height-5.2 mm; NaX sizes: diameter- $4.2 \mathrm{~mm}$, height- $4.4 \mathrm{~mm}$. Thus the equivalent adsorbent diameter (proportional to the ratio of the grain to its external surface) was approximately the same and amounted to $\mathrm{d}_{\mathrm{e}}=4.0 \div 4.2 \mathrm{~mm}$.

\subsection{Effect of Layer Height on the Adsorption Characteristics of the Samples $\mathrm{Al}_{2} \mathrm{O}_{3}$ and $\mathrm{NaX}$}

The results (Table 1) were obtained at a gas consumption rate of $25 \mathrm{~L} / \mathrm{min}$ (gas velocity was $0.21 \mathrm{~m} / \mathrm{s}$ ), pressure of $0.1 \mathrm{MPa}$ and water concentration at the entrance of $14.6 \div 15.5 \mathrm{~g} / \mathrm{m}^{3}$. To compare the results, the layer retention time was reduced to $15 \mathrm{~g} / \mathrm{m}^{3}$, which corresponded to $100 \%$ of humidity at $18{ }^{\circ} \mathrm{C}$.

Table 1. Influence of the desiccant layer height on adsorption characteristics.

\begin{tabular}{cccccc}
\hline $\begin{array}{c}\text { No. of } \\
\text { Experiment }\end{array}$ & $\begin{array}{c}\text { Adsorbent Volume, } \\
\mathbf{L}\end{array}$ & $\begin{array}{c}\text { Layer Height, } \\
\mathbf{c m}\end{array}$ & $\begin{array}{c}\text { Water Content, } \\
\mathbf{g} / \mathbf{m}^{\mathbf{3}}\end{array}$ & $\begin{array}{c}\text { Minimal } \\
\mathbf{T}_{\mathbf{d . p} .}{ }^{\mathbf{o}} \mathbf{C}\end{array}$ & $\begin{array}{c}\mathbf{D C}, \\
\mathbf{g} / \mathbf{1 0 0}{\mathbf{~} \mathbf{m}^{\mathbf{3}}}^{\mathbf{2}}\end{array}$ \\
\hline 1 & 0.3 & 15.3 & 15.07 & -59.5 & 3.77 \\
\hline 2 & 0.6 & 30.6 & 15.11 & -55.5 & 6.9 \\
\hline 3 & 0.9 & 46.0 & 15.91 & -60.9 & 9.5 \\
\hline 4 & 0.9 & 46.0 & 14.94 & -65.3 & 7.55 \\
\hline 5 & 1.2 & 61.0 & 15.6 & -60.1 & 11.31 \\
\hline 6 & & $\mathrm{NaX}$ & & & 3.3 \\
\hline 7 & 0.3 & 15.3 & 14.67 & -49.3 & 8.53 \\
\hline 8 & 0.6 & 30.6 & 14.72 & -48.7 & 9.13 \\
\hline 9 & 0.6 & 30.6 & 15.2 & -60.2 & 11.66 \\
\hline 10 & 0.9 & 46.0 & 14.57 & -60.9 & 12.17 \\
\hline
\end{tabular}

When the height of the adsorbent layer increases, its adsorption capacity also increases (Table 1). The protective power time of the layer increases at the expense of the increase in the dynamic capacity and the adsorbent volume. Since the weight by volume of the zeolite-based adsorbent is almost 1.5 times less than that of aluminium oxide, the dynamic capacity related to the gram of the adsorbent is greater (Figure 3); however, the protective power time of the layers of different adsorbents is comparable (Figure 4). 


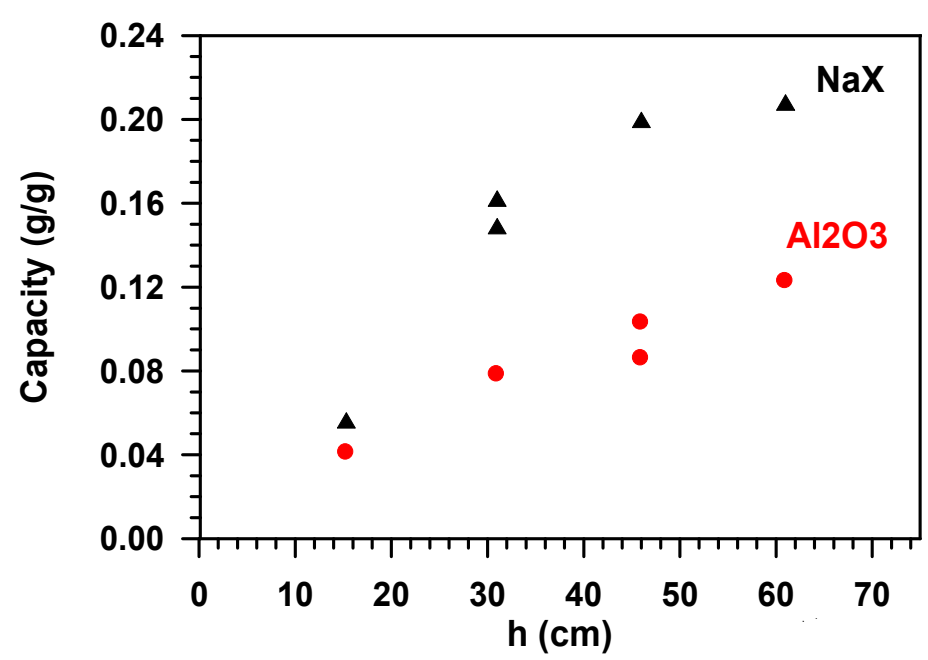

Figure 3. Experimental data of the dependence of the dynamic capacity of the layers in adsorbents $\mathrm{Al}_{2} \mathrm{O}_{3}$ and $\mathrm{NaX}$ on the height (conditions: the saturator temperature is $18{ }^{\circ} \mathrm{C}$, pressure is $0.1 \mathrm{MPa}$ ).

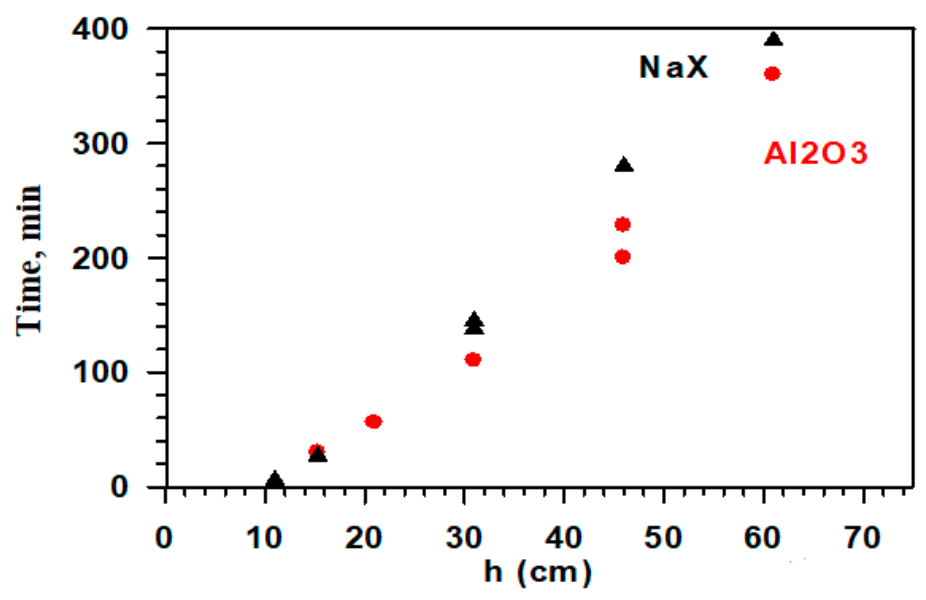

Figure 4. Experimental data of the dependence of the protective power time of the layers of adsorbents $\mathrm{Al}_{2} \mathrm{O}_{3}$ and $\mathrm{NaX}$ on the layer height (conditions: the saturator temperature is $18^{\circ} \mathrm{C}$, pressure is $0.1 \mathrm{MPa}$ ).

3.3. Data on the Influence of the Pressure on the Adsorption Characteristics of the Samples $\mathrm{Al}_{2} \mathrm{O}_{3}$ and $\mathrm{NaX}$

Experimental conditions: water concentration at the entrance-14.6 $\div 15.5 \mathrm{~g} / \mathrm{m}^{3}$, grain diameter- $\mathrm{d}_{\mathrm{e}}$ $=4.0 \div 4.2 \mathrm{~mm}$, adsorbent layer height-30.6 cm, adsorbent volume-0.6 L gas consumption- $25 \mathrm{~L} / \mathrm{min}$. The results of the conducted experiments are presented in Table 2, in Figures 5-7.

Table 2. Dependence of adsorption characteristics of $\mathrm{Al}_{2} \mathrm{O}_{3}$ and $\mathrm{NaX}$ on pressure.

\begin{tabular}{|c|c|c|c|c|}
\hline \multirow{2}{*}{ No. of Experiment } & \multirow{2}{*}{$\mathbf{P}, \mathbf{M P a}$} & \multirow{2}{*}{ Minimal $\mathrm{T}_{\mathrm{d} . \mathrm{p} .},{ }^{\circ} \mathrm{C}$} & DC & \multirow{2}{*}{ Adsorbent Type } \\
\hline & & & $\mathrm{g} / 100 \mathrm{~g}$ & \\
\hline 1 & 0.1 & -55.5 & 7.83 & \multirow{6}{*}{$\mathrm{Al}_{2} \mathrm{O}_{3}$} \\
\hline 2 & 0.2 & -57.8 & 14.12 & \\
\hline 3 & 0.3 & -65.0 & 18.73 & \\
\hline 4 & 0.4 & -59.0 & 19.15 & \\
\hline 5 & 0.5 & -59.9 & 19.18 & \\
\hline 6 & 0.6 & -60.2 & 19.30 & \\
\hline
\end{tabular}


Table 2. Cont.

\begin{tabular}{|c|c|c|c|c|}
\hline \multirow{2}{*}{ No. of Experiment } & \multirow{2}{*}{$\mathrm{P}, \mathrm{MPa}$} & \multirow{2}{*}{$\operatorname{Minimal} \mathrm{T}_{\text {d.p. }}{ }^{\circ} \mathrm{C}$} & DC & \multirow{2}{*}{ Adsorbent Type } \\
\hline & & & $\mathrm{g} / 100 \mathrm{~g}$ & \\
\hline 7 & 0.1 & -48.7 & 14.79 & \multirow{5}{*}{$\mathrm{NaX}$} \\
\hline 8 & 0.2 & -60.5 & 21.11 & \\
\hline 9 & 0.3 & -59.1 & 23.09 & \\
\hline 10 & 0.5 & -63.2 & 19.46 & \\
\hline 11 & 0.6 & -60.4 & 16.95 & \\
\hline
\end{tabular}

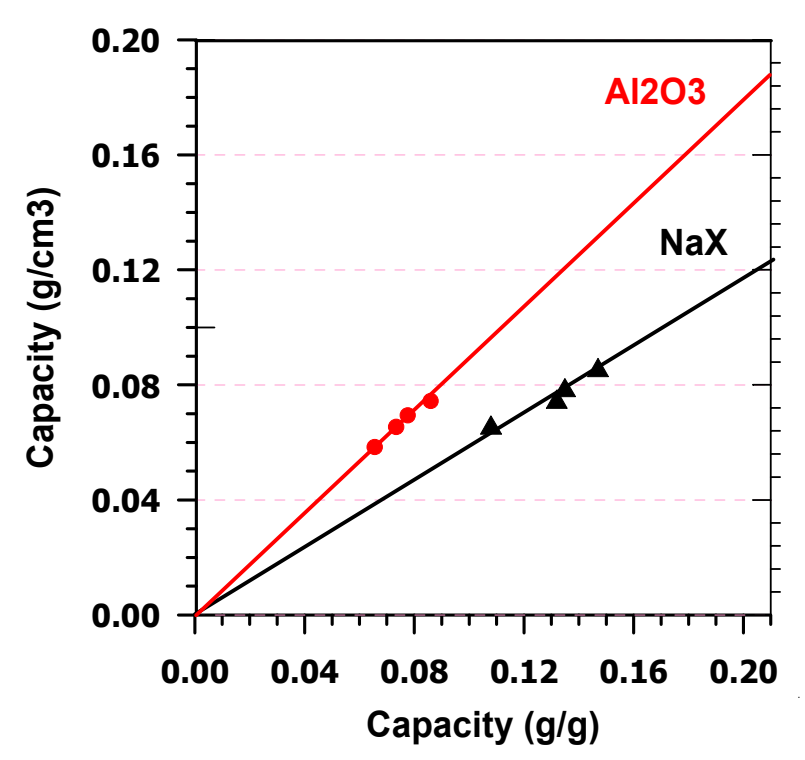

Figure 5. Correlation between the experimentally measured values of the dynamic capacity of the adsorbents $\left(\mathrm{Al}_{2} \mathrm{O}_{3}\right.$ and $\left.\mathrm{NaX}\right)$ with respect to water vapour, classified as a unit of their volume and a mass unit (conditions: the saturator temperature is $18{ }^{\circ} \mathrm{C}$, pressure is $0.1 \div 0.6 \mathrm{MPa}$ ).

The linear dependence between the experimentally measured values of the dynamic capacity of the adsorbents $\left(\mathrm{Al}_{2} \mathrm{O}_{3}\right.$ and $\left.\mathrm{NaX}\right)$ with respect to water vapour, classified as a unit of their volume and a mass unit (Figure 5), indicates that the density of the layer filling (and, as a consequence, porosity) in different experiments was the same. This figure shows that the averaged weight by volume of the adsorbents $\left(\rho_{\mathrm{Al} 2 \mathrm{O} 3}\right.$ and $\left.\rho_{\mathrm{NaX}}\right)$ can be estimated from the ratio of dynamic capacities classified as a volume unit and a mass unit, i.e.:

$$
\begin{gathered}
\rho_{\text {Al2O3 }}=\frac{D E, \mathrm{~g} / \mathrm{cm}^{3}}{\mathrm{DE}, \mathrm{g} / \mathrm{g}}=\frac{15.6}{18} \approx \frac{15.6}{18} \approx 0.87 \frac{\mathrm{g}}{\mathrm{cm}^{3}}, \\
\rho_{\mathrm{NaX}}=\frac{D E, \mathrm{~g} / \mathrm{cm}^{3}}{\mathrm{DE}, \mathrm{g} / \mathrm{g}}=\frac{10.6}{18} \approx 15.6 / 18 \approx 0.59 \frac{\mathrm{g}}{\mathrm{cm}^{3}},
\end{gathered}
$$

In the case under consideration, another criterion of the "consistency" of the experimental data is the presence of the correlation between the protective power time of the layer and the dynamic capacity of the adsorbents (Figure 6). The linear dependence between the experimentally measured values of the protective power time of the layer and the dynamic capacity of the adsorbents $\left(\mathrm{Al}_{2} \mathrm{O}_{3}\right.$ and $\mathrm{NaX}$ ) with respect to water vapour bears evidence of the properly obtained data. The protective power time of the layer was reduced to the water content at the entrance- $15 \mathrm{~g} / \mathrm{cm}^{3}$. 


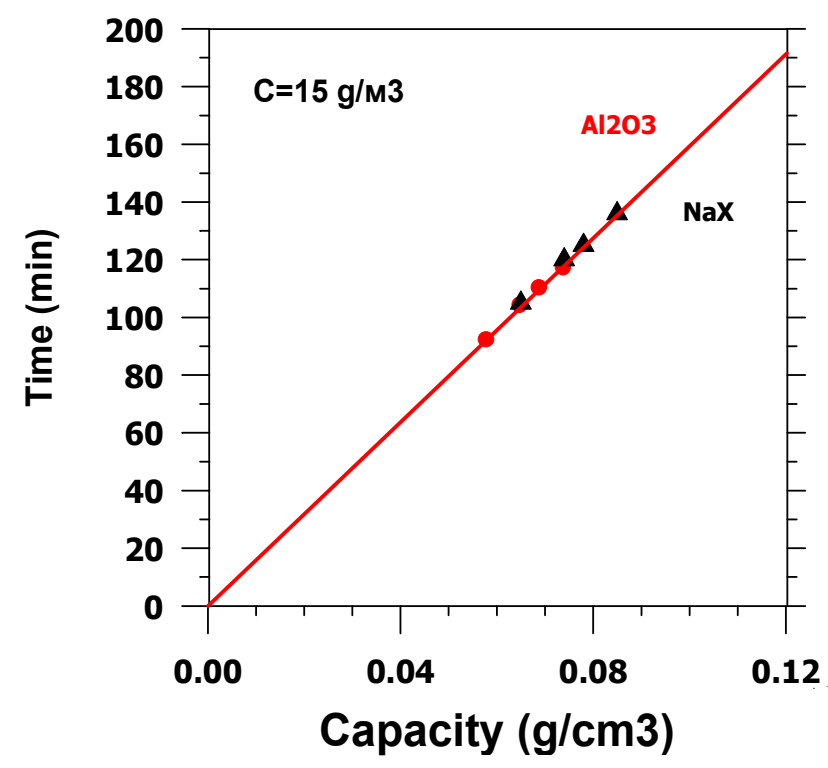

Figure 6. Correlation between the experimentally measured values of the protective power time of the layer and the dynamic capacity of the adsorbent $\left(\mathrm{Al}_{2} \mathrm{O}_{3}\right.$ and $\left.\mathrm{NaX}\right)$ volume with respect to water vapour. Circular symbols $-\mathrm{Al}_{2} \mathrm{O}_{3}$, triangle symbols- $\mathrm{NaX}$ (conditions: the saturator temperature is $18^{\circ} \mathrm{C}$, pressure is $0.1 \div 0.6 \mathrm{MPa}$ ).

Figure 7 shows that when the pressure increases, in this case-to $0.3 \mathrm{MPa}$, the dynamic capacity and, respectively, the protective power time of the adsorbent layer increase proportionally. The data in Figure $7 \mathrm{~b}$ were obtained from Table 2, taking into account the specific weight of the adsorbents $\left(\rho \mathrm{Al}_{2} \mathrm{O}_{3}=0.87 \mathrm{~g} / \mathrm{cm}^{3} ; \rho \mathrm{NaX}=0.59 \mathrm{~g} / \mathrm{cm}^{3}\right)$.

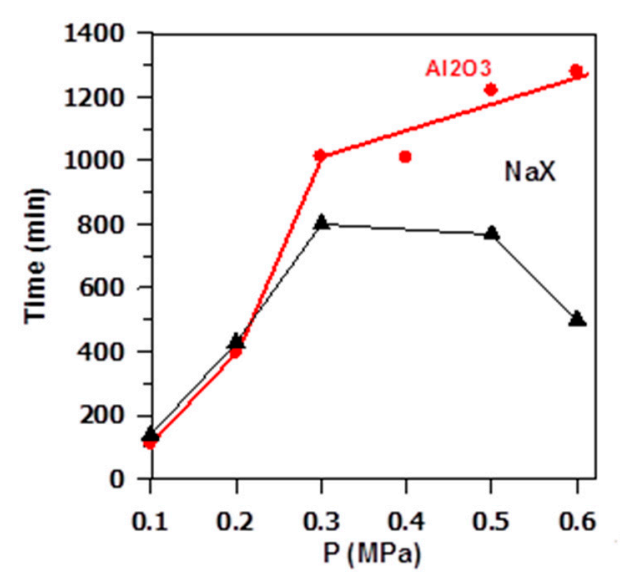

(a)

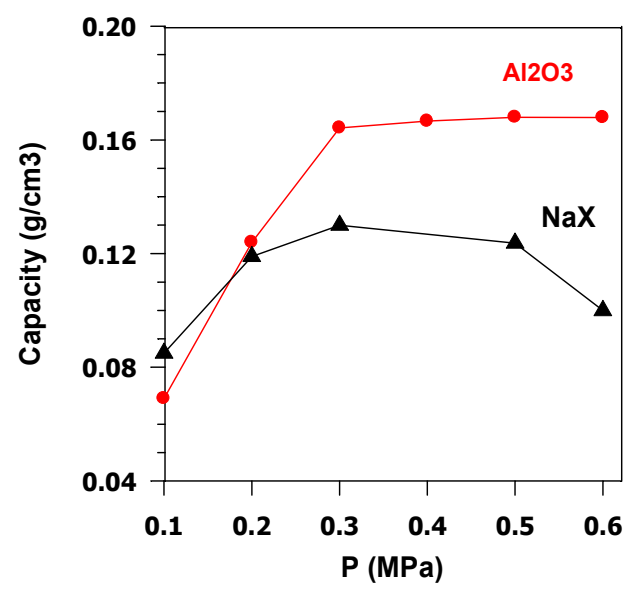

(b)

Figure 7. Dependence of the protective power time of the adsorbent layer (a) and their dynamic capacity with respect to water vapour $(\mathbf{b})$ on pressure (conditions: the saturator temperature is $18{ }^{\circ} \mathrm{C}$ ).

At the atmospheric pressure, the adsorption characteristics of the $\mathrm{NaX}$ adsorbent are better than those of the aluminium oxide adsorbent. However, at a pressure of $0.3 \mathrm{MPa}$ the situation changes-the adsorption capacity and the protective power time of the adsorbent $\mathrm{Al}_{2} \mathrm{O}_{3}$ increase. The presence of the maximum dynamic capacity of the adsorbent with increasing pressure, which was observed for $\mathrm{NaX}$ (Figure 7b), was previously noted for other adsorbents, such as silica gel KSM-6 and zeolite NaA. Apparently, this may be due to the complex mutual influence of the rate of diffusion processes and flow turbulence with increasing pressure [6]. Another reason for the observed decrease in capacity with 
increasing pressure may be associated with the fact that the measured capacity is an excess capacity, not an absolute capacity.

To compare the data, for each pressure value in the studied range of $0.1 \div 0.6 \mathrm{MPa}$, the value of the protective power time of the layer (PPT) in Figure 7a was reduced to the concentration of one of the adsorbents $-\mathrm{Al}_{2} \mathrm{O}_{3}$. That is, the experimentally obtained value of PPT for $\mathrm{NaX}$ was multiplied by the concentration of water vapour in the air flow $\left(\mathrm{C}_{\mathrm{H} 2 \mathrm{O}}\right)_{\mathrm{NaX}}$ and divided by $\left(\mathrm{C}_{\mathrm{H} 2 \mathrm{O}}\right)_{\mathrm{Al} 2 \mathrm{O} 3}$.

As a result of the conducted research on the pilot installation, the equilibrium values of the adsorption capacity for the oxide-based adsorbent $\left(\mathrm{Al}_{2} \mathrm{O}_{3}\right)$ and the commercial adsorbent (zeolite $\mathrm{NaX}$ ) were specified. The obtained data on the laboratory unit and the pilot installation are in good agreement (Figure 8) with the results of the dynamic capacity determination.

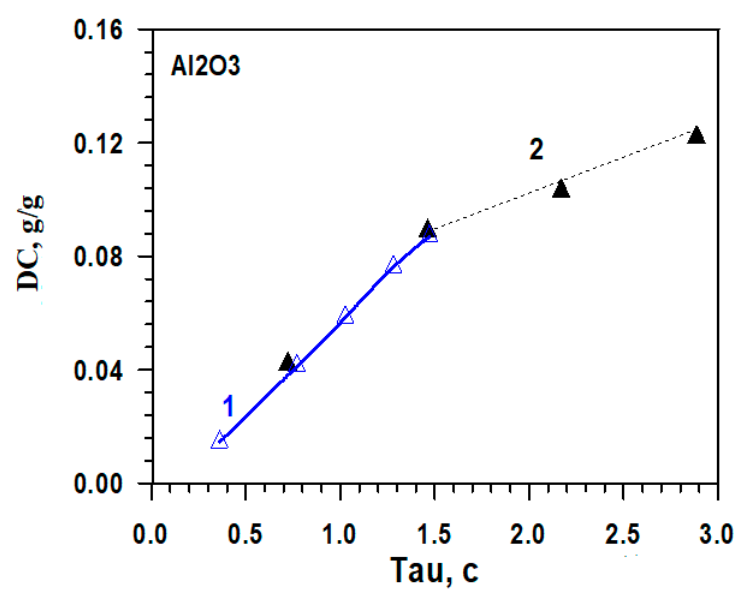

Figure 8. Dependence of the dynamic capacity of the prospective aluminium oxide adsorbent $\left(\mathrm{Al}_{2} \mathrm{O}_{3}\right)$ on the contact time at a water concentration of $15 \mathrm{~g} / \mathrm{m}^{3}$ at the entrance. 1-data of the laboratory unit (air consumption-8.2 L/min); 2-data of the pilot installation (air consumption-25 L/min). Conditions: the saturator temperature is $18^{\circ} \mathrm{C}$, pressure is $0.1 \mathrm{MPa}$.

\section{Conclusions}

Based on the obtained experimental data, the equilibrium values of the adsorption capacity for the adsorbent, based on the oxide $\mathrm{Al}_{2} \mathrm{O}_{3}$, and the commercial adsorbent (zeolite $\mathrm{NaX}$ ), the values of the averaged weight by volume of the adsorbents, used in the work, were estimated. When the layer height of the adsorbents under study increases, their dynamic capacity with respect to water vapour and the protective power time increase. At the atmospheric pressure, the adsorption characteristics of the adsorbent $\mathrm{NaX}$ are better than those of the aluminium oxide adsorbent, and the protective power time of the layers of different adsorbents is comparable. However, at a pressure higher than $0.3 \mathrm{MPa}$, things are different-the adsorption capacity and the protective power time of the developed adsorbent $\mathrm{Al}_{2} \mathrm{O}_{3}$ increase. Consequently, the use of this aluminium oxide adsorbent, taking into account its higher resistance to moisture, lower cost and lower regeneration temperature, is preferable as compared with other zeolite-based analogues during dewatering under pressure.

Author Contributions: This paper was accomplished based on the collaborative work of the authors. E.M. and A.L. wrote the article. M.K. and S.R. performed the experiments, analysed the data and interpreted the experimental results. I.K. and L.I. supervised the entire research progress. All authors have read and agreed to the published version of the manuscript.

Funding: The research was funded by the Ministry of Science and Higher Education, grant number “0721-2020-0037".

Conflicts of Interest: The authors declare no conflict of interest. 


\section{References}

1. Mamaliga, I.; Baciu, C.; Petrescu, S. Study of adsorption equilibrium of some wet air-composite material systems. Environ. Eng. Manag. J. 2009, 8, 253-257.

2. Nakabayashi, S.; Nagano, K.; Nakamura, M.; Togawa, J.; Kurokawa, A. Improvement of water vapor adsorption ability of natural mesoporous material by impregnating with chloride salts for development of a new desiccant filter. Adsorption 2011, 17, 675-686. [CrossRef]

3. Kong, L.; Adidharma, H. A new adsorption model based on generalized van der Waals partition function for the description of all types of adsorption isotherms. Chem. Eng. J. 2019, 375, 112-122. [CrossRef]

4. Mahmoud, D.; Salleh, M.; Karim, W. Langmuir model application on solid-liquid adsorption using agricultural wastes: Environmental application review. J. Purity Util. React. Environ. 2012, 1, 170-199.

5. Kudra, T.; Mujumdar, A. Advanced Drying Technologies; Taylor \& Frances: London, UK, 2009.

6. Keltsev, N.V. Fundamentals of Adsorption Technology; Khimiya: Moscow, Russia, 1984; p. 595.

7. Ribeiro, A.M.; Sauer, T.P.; Grande, C.A.; Moreira, R.F.P.M.; Loureiro, J.M.; Rodrigues, A.E. Adsorption Equilibrium and Kinetics of Water Vapour on Different Adsorbents. Ind. Eng. Chem. Res. 2008, 47, 7019-7026. [CrossRef]

8. Do, D.D. Adsorption Analysis: Equilibria and Kinetics; Series on Chemical Engineering; World Scientific: Singapore, 1998; Volume 2, p. 916.

9. Ralph, T. Yang. Gas Separation by Adsorption Processes; Butterworth: Boston, MA, USA, 1987; p. 353.

10. Dambrowski, A. Adsorption-From theory to practice. Adv. Colloid Interface Sci. 2001, 93, 135-224. [CrossRef]

11. Filho, N.L.D.; Carmo, D.R.D. Adsorption at Silica, Alumina, and Related Surfaces. Encycl. Surf. Colloid Sci. 2006, 1-20. [CrossRef]

12. Sircar, S.; Rao, M.B.; Golden, T.C. Drying of gases and liquids by activated alumina. Stud. Surf. Sci. Catal. 1996, 99, 629-646.

13. Knaebel, K.S. Adsorbent Selection. 2002. Available online: https://userpages.umbc.edu/ \{\}dfrey1/ench445/ AdsorbentSel1B.pdf (accessed on 15 June 2020).

14. Ducreux, O.; Lavigne, C.; Nedez, C. Air and Gas Drying with Activated Aluminas. 2011. Available online: http://www.cabestisrl.com.ar/AirGas\%20Drying\%20Brochure.pdf (accessed on 25 May 2020).

15. Busca, G. The surface of transitional aluminas: A critical review. Catal. Today 2014, 226, 319-404. [CrossRef]

16. Tanashev, Y.Y.; Moroz, E.M.; Isupova, L.A.; Ivanova, A.S.; Litvak, G.S.; Amosov, Y.I.; Rudina, N.A.; Shmakov, A.N.; Stepanov, A.G.; Kharina, I.V.; et al. Synthesis of aluminum oxides from the products of the rapid thermal decomposition of hydrargillite in a centrifugal flash reactor: II. Physicochemical properties of the products obtained by the centrifugal thermal activation of hydrargillite. Kinet. Catal. 2007, 48, $153-161$. [CrossRef]

17. Danilevich, V.V.; Isupova, L.A.; Kagyrmanova, A.P.; Kharina, I.V.; Zyuzin, D.A.; Noskov, A.S. Highly effective water adsorbents based on aluminum oxide. Kinet. Catal. 2012, 53, 632-639. [CrossRef]

18. Danilevich, V.V.; Isupova, L.A.; Paukshtis, E.A.; Ushakov, V.A. Effect of modifying alumina desiccants with sulfuric acid on their physicochemical properties. Kinet. Catal. 2014, 55, 372-379. [CrossRef]

19. Danilevich, V.V.; Isupova, L.A.; Danilova, I.G.; Zotov, R.A.; Ushakov, V.A. Characteristics optimization of activated alumina desiccants based on product of a centrifugal thermal activation of gibbsite. Russ. J. Appl. Chem. 2016, 89, 343-353. [CrossRef]

20. Isupova, L.A.; Danilova, I.G.; Danilevich, V.V.; Ushakov, V.A. Enhancement of the Sorption Ability of Aluminum Oxide Desiccants by Alkaline Modification. Russ. J. Appl. Chem. 2017, 90, 1810-1818. [CrossRef]

21. Livanova, A.; Meshcheryakov, E.; Reshetnikov, S.; Reshetnikov, I. Study of water vapour adsorption kinetics on aluminium oxide materials. AIP Conf. Proc. 2017. [CrossRef]

22. Zotov, R.A.A.; Isupova, L.A.A.; Danilevich, V.V.V.; Babina, A.A.; Sinel'nikov, A.N.; Meshcheryakov, E.P.; Kurzina, I.A. Dynamic Capacity of Desiccants Based on Modified Alumina at Elevated Pressures. Catal. Ind. 2017, 9, 91-98. [CrossRef]

23. Zotov, R.; Meshcheryakov, E.; Livanova, A.; Minakova, T.; Magaev, O.; Isupova, L.; Kurzina, I. Influence of the Composition, Structure, and Physical and Chemical Properties of Aluminium-Oxide-Based Sorbents on Water Adsorption Ability. Materials 2018, 11, 132. [CrossRef] 
24. Reshetnikov, S.I.; Meshcheryakov, E.P.; Isupova, L.A.; Livanova, A.V.; Kurzina, I.A. Effect of Li, Na and K modification of alumina on its physical and chemical properties and water adsorption ability. Materials 2019, 12, 4212. [CrossRef]

25. Reshetnikov, S.I.; Budaev, Z.B.; Livanova, A.V.; Meshcheryakov, E.P.; Kurzina, I.A. Effect of particle size on adsorption kinetics of water vapor on porous aluminium oxide material. JPCS 2019, 1145, 1-8. [CrossRef]

26. Livanova, A.V.; Meshcheryakov, E.P.; Reshetnikov, S.I.; Kurzina, I.A. Influence of alkaline modification on adsorption properties of alumina. JPCS 2019, 1145, 1-8. [CrossRef]

27. Reshetnikov, S.I.; Livanova, A.V.; Meshcheryakov, E.P.; Kurzina, I.A.; Isupova, L.A. Kinetic Aspects of the Adsorption on Aluminum Oxide Drying Agents Doped with Alkali Metal Ions. Russ. J. Appl. Chem. 2017, 90, 1760-1765. [CrossRef]

28. Livanova, A.V.; Budaev, Z.B.; Meshcheryakov, E.P.; Reshetnikov, S.I.; Isupova, L.A.; Kurzina, I.A. Synthesis of aluminum-oxide adsorbents using alkalis at the hydration stage and study of their physicochemical and adsorptive properties. IOP Conf. Ser. Mater. Sci. Eng. 2019, 597, 1-5. [CrossRef]

29. Livanova, A.V.; Sandu, M.P.; Budaev, Z.B.; Meshcheryakov, E.P. Comparative assessment of characteristics of industrial and laboratory highly-efficient samples of adsorbents-desiccants. IOP Conf. Ser. Mater. Sci. Eng. 2019, 696, 1-6. [CrossRef]

30. Kruglyakov, V.Y.; Glazyrin, A.V.; Mescheryakov, E.P.; Kurzina, I.A.; Isupova, L.A. A High-Performance Alumina Desiccant. Catal. Ind. 2019, 19, 421-429. [CrossRef]

(C) 2020 by the authors. Licensee MDPI, Basel, Switzerland. This article is an open access article distributed under the terms and conditions of the Creative Commons Attribution (CC BY) license (http://creativecommons.org/licenses/by/4.0/). 